promine $60 \mathrm{mg} /$ day and New York State Cheddar cheese $60-90 \mathrm{~g}$ daily. This patient had been unable to sit up for more than $30 \mathrm{sec}$. On treatment he could sit up for $6 \mathrm{hr}$ daily and stand for short periods. Finally one ought to mention the report of Hunter et al. (1970) who took a normotensive patient, established on a steady dose of phenelzine $45 \mathrm{mg} / \mathrm{d}$ for 10 days, and administered one $50 \mathrm{mg}$ dose of levodopa orally. The BP rose from 130/90 to $200 / 130 \mathrm{mmHg}$ in $1 \mathrm{hr}$ when the procedure was stopped and treatment with $9 \mathrm{mg}$ of phenoxybezamine restored the BP to normal.

\section{Conclusions}

Our patient had no compensatory vasoconstriction to combat postural hypotension. Pharmacological studies suggest that significant vasoconstriction can be produced by agents acting on the vessels directly. His postural hypotension therefore suggests that the lesion lies proximally and it is suggested that the amyloid deposits in the ganglia and/or peripheral nerves may be responsible for insufficient sympathetic efferent effect. This lesion is similar in site to lesions inferred by physiological studies by Bannister in the analogous situation of idiopathic postural hypotension, and suspected as a result of biochemical studies, and of anatomical studies showing cellular fallout in the central connections of the autonomic nervous system.

\section{References}

Bannister, R., Ardill, L. \& Fenton, P. (1967) Defective autonomic control of blood vessels in idiopathic ortho- $\frac{Q}{C}$ static hypotension. Brain, 90, 725.

Diamond, M.A., Murray, R.H. \& Schmid, P.G. (1970) Idiopathic postural hypotension. Physiologic observation $\overline{0}$ and report of a new mode of therapy. Journal of Clinical $\bar{\square}$ Investigation, 49, 1341.

Gordon, R.D., Kuchell, O., Liddle, G.W. \& Island, D.P. $\overrightarrow{\widehat{D}}$ (1967) Role of the sympathetic nervous system in regulat- $Q$ ing renin and aldosterone production. Journal of Clinical Investigation, 46, 599.

Hunter, K.R., Boakes, A.J., Laurence, D.R. \& Stern, ? G.M. (1970) Monoamine oxidase inhibitors and levodopa. $\vec{\omega}$ British Medical Journal, 3, 388.

Kyle, R.A., KottKe, B.A. \& Schirger, A. (1966) Orthostatic hypotension as a clue to primary systemic amyloid. 3 Circulation, 34, 883.

LUFT, R. \& voN EULER, UlF.S. (1955) Diminished excretion iv of norepinephrine and epinephrine in two cases of orthostatic postural hypotension. Journal of Clinical Investi- ir gation, 32, 1065.

McC. Goodall, Harlan, W.R. \& Alton, H. (1968) 을 Decreased noradrenaline synthesis in neurogenic ortho- static hypotension. Circulation, 38, 592.

Munsat, T.L. \& Poussaint, A.F. (1962) Clinical manifestations and diagnosis of amyloid polyneuropathy. 를 Neurology, 12, 413.

SELler, R.H. (1969) Idiopathic orthostatic hypotensio o Report of successful treatment with a new form of therap American Journal of Cardiology, 23, 838.

\title{
Carcinoma of the pancreas and hyperosmolar coma
}

\author{
ANDREW G. CUDWORTH \\ M.B., M.R.C.P. (U.K.) \\ David Lewis Northern Hospital, Liverpool
}

\begin{abstract}
Summary
A case of hyperosmolar coma with carcinoma of the pancreas is reported. There appears to be no previous report of this association.
\end{abstract}

THE association of carcinoma of the pancreas with late onset 'brittle' diabetes is well recorded, but there appears to be no previous report of carcinoma of the pancreas presenting as a non-ketotic diabetic coma.

\section{Case report}

The patient, a white male, aged 76 years was admitted in an unconscious state, responding only to painful stimuli. Four days earlier he had presented to his general practitioner with a 5 weeks' history of general malaise, weakness, epigastric discomfort and loss of appetite. His wife noted that recently he had taken only soups, but during the week prior to admission he had stopped eating altogether, and over the preceding 2 days had progressively drifted into a state of unconsciousness. There were no previous illnesses of note, and no family history of diabetes mellitus.

On examination he was of lean build with signs of marked dehydration. He was afebrile with a normal pulse, blood pressure and quiet respiration. There was a striking increase in tone in all four limbs, neck rigidity and conjugate deviation of the 
eyes to the right. The liver was enlarged to $3 \mathrm{~cm}$ below the costal margin and there was sufficient tenderness in the epigastrium to arouse resistance during examination. Bowel sounds were normal.

Investigations. Blood sugar $604 \mathrm{mg} / 100 \mathrm{ml}$; plasma sodium $174 \mathrm{mEq} / \mathrm{l}$; plasma chloride 119 $\mathrm{mEq} / 1$; plasma potassium $3.0 \mathrm{mEq} / 1$; plasma bicarbonate $31.2 \mathrm{mEq} / \mathrm{l}$; blood urea $162 \mathrm{mg} / 100 \mathrm{ml}$; Hb $16.9 \mathrm{~g} / 100 \mathrm{ml}$; PCV 56\%; serum amylase 800 Somogyi units; catheter specimen of urine contained $2 \%$ sugar, no ketones or protein. A lumbar puncture produced a clear CSF of normal pressure with no increase in cells. A chest radiograph showed no abnormality. ECG: flat or inverted $T$ waves and $U$ waves in all leads. Using the formula

$(\mathrm{mOsmol})=2 \times \mathrm{Na}^{+}(\mathrm{mEq} / \mathrm{l})+\frac{\text { glucose } \mathrm{mg} / 100 \mathrm{ml}}{18}$

the calculated plasma osmolarity $=382 \mathrm{mOsmol}$.

Treatment and progress. The total duration of the illness after admission was $32 \mathrm{hr}$. Intravenous therapy had been commenced with 1 litre of $5 \%$ dextrose and this was followed by 91 of hypotonic (one-fifth normal) saline and a further 1 litre of $5 \%$ dextrose, making a total of 11 litres. At no time did the central venous pressure rise above $+3 \mathrm{~cm}$. Potassium chloride was added to each litre (total given: $33 \mathrm{~g}$ ), and careful monitoring of plasma electrolytes, blood urea, blood sugar and urinary output was maintained throughout. The hypernatraemia was corrected within $6 \mathrm{hr}$, but the plasma potassium showed only a slow return towards the normal range despite the large amounts given. Although a total of $1365 \mathrm{ml}$ of urine was passed with persistent absence of ketones and diminishing glycosuria, the blood urea did not fall below $162 \mathrm{mg} / 100 \mathrm{ml}$. The blood sugar remained high $(500-696 \mathrm{mg} / 100 \mathrm{ml})$ up to $18 \mathrm{hr}$, and it was therefore decided to give soluble insulin in three doses of 50,50 and 100 units intravenously at 18,22 and $24 \mathrm{hr}$ respectively. The initial avoidance of insulin was a deliberate policy as it has been claimed (see discussion) that rehydration alone is sufficient to correct the hyperglycaemia in this type of coma.

Although the patient never fully recovered he showed signs of clinical as well as biochemical improvement. The increased tone and neck rigidity disappeared and he was able to obey simple commands. Despite having an antibiotic (parenteral ampicillin) throughout, he developed signs of a bronchopneumonia, followed by rapid deterioration and death.

Necropsy ( $12 \mathrm{hr}$ later) confirmed that the cause of death was bronchopneumonia. The pancreas contained a large carcinoma in the first part of the body, not involving the common bile duct, but there was thrombosis of the splenic vein and its hepatic branches. The liver was enlarged and contained secondary deposits. The spleen was normal and the brain showed no evidence of compression or oedema. Histological examination of the tumour revealed a poorly differentiated adenocarcinoma. There was evidence of distal pancreatitis and fat necrosis but large parts of the pancreas were histologically normal.

\section{Discussion}

The condition of hyperglycaemic non-ketotic coma is an uncommon complication of diabetes mellitus, and any hope of successful treatment depends on early recognition. The features of the condition are now well known and commonly include severe dehydration, hyperglycaemia, hypernatraemia and resultant hyperosmolarity, leading to insidious coma with varying levels of consciousness (Halmos, Nelson \& Lowry, 1966). As in the present case ketosis and Kussmaul respiration are absent. The condition commonly affects the elderly and is often the first manifestation of carbohydrate intolerance. The mortality is high. Di Benedetto, Crocco \& Soscia (1965) reported it as high as $44 \%$, but in those who survive the subsequent pattern of diabetes is mild, often controlled by diet alone with little recourse to insulin. Clinical features observed during the coma phase include increased tone, neck rigidity, focal seizures, aphasia and even hemiparesis (Macarrio, Messis \& Vastola, 1965). These signs probably reflect severe cellular dehydration since the brain appears normal at necropsy. A similar mechanism may also account for the frequently reported incidence of pancreatitis (10-20\%) in this condition. Other complications not seen in this case include arterial thrombosis and renal failure (Halmos et al., 1966).

In recent years various precipitating causes have been recorded including corticosteroid therapy (Boyer, 1967; Kumar, 1968; Spenney, Eure \& Kreisberg, 1969), diphenylhydantoin (Goldberg \& Sanbar, 1969), peritoneal dialysis (high-glucosecontent fluids), and stress situations such as pancreatitis, sepsis and burns. The aetiology in the majority of cases however remains obscure. Johnson et al. (1969) found in one case a low level of plasma immunoreactive insulin before treatment and suggested that there was just enough endogenous insulin to suppress ketosis but insufficient to control blood glucose. In another case report (Vanik, Joffe \& Joubert, 1970), no immunoreactive plasma insulin could be detected. Another suggestion (Henry \& Bressler, 1968) is that massive hyperglycaemia permits sufficient glucose utilization and inhibits release of fatty acids, thus preventing ketosis.

There has in the past been little general agreement about the management of this type of diabetic coma. Most authors emphasize the need for large volumes 
of intravenous fluid (on average 121 in $24 \mathrm{hr}$ ), but there is less unanimity about what type of fluid should be administered. Hayes \& Woods (1968) describe a single case treated successfully with isotonic fluids alone, without insulin. Despite giving generous volumes of hypotonic fluid in this case the blood sugar remained high until insulin was also administered. The use of large volumes of hypotonic solutions, initially half strength saline (i.e. $0 \cdot 45 \%$ ), then glucose $(2.5 \%)$, together with soluble insulin from the outset now seems to be the generally accepted practice. A central venous pressure line is desirable in view of the large volume of fluid to be given, and a careful watch should be maintained on plasma sodium and potassium as this will give a guide to the amount of particular hypotonic fluid to be used. The insulin requirement varies considerably from person to person. Routine use of heparin is also advocated to avoid major vascular thromboses and plasma expanders may be used initially to prevent renal failure.

The association of diabetes mellitus and carcinoma of the pancreas is well recognized; (Pygott \& Osborn, 1937; Clark \& Mitchell, 1961). In a review of necropsy records, Bell (1957) showed that whereas carcinoma in general occurred less often in diabetics, the incidence of pancreatic carcinoma was twice as great as in non-diabetics. Clark \& Mitchell (1961) found diabetes of recent onset in 15.3\% of cases of carcinoma of the pancreas and drew attention to a group of elderly patients who present with a more unstable form of maturity onset diabetes accompanied by a tendency to ketosis, and usually with a negative family history. Although being 'brittle', coma was not found to be a complication. Karmody \& Kyle (1969) found that the symptoms attributable to diabetes nearly always present first with the symptoms attributable to the carcinoma appearing within 3 months in $50 \%$, and in $80 \%$ within 1 year. Thus, the presentation of a patient with a carcinoma of the pancreas in a diabetic coma and in particular a non-ketotic coma seems to be a rare phenomenon and not previously recorded.

\section{Acknowledgment}

I am grateful to Dr B. A. Walker, Consultant Physician, David Lewis Northern Hospital, for his constructive comments and help in the preparation of this article.

\section{References}

BeLL E.T.(1957) Carcinoma of the pancreas: I. A clinical and pathological study of 609 necropsied cases. II. The relation of carcinoma of the pancreas to diabetes mellitus. American Journal of Pathology, 33, 499.

BOYER, M.H. (1967) Hyperosmolar anacidotic coma in association with glucocorticoid therapy. Journal of the American Medical Assocaition, 202, 1007.

Clark, C.G. \& Mitchell, P.E.G. (1961) Diabetes mellitus and primary carcinoma of the pancreas. British Medical Journal, 2, 1259.

di Benedetto, R.J., Crocco, J.A. \& Soscia, J.L. (1965) Hyperglycaemic non-ketotic coma. Archives of Internal Medicine, 116, 74.

GoldberG, E.M. \& SANBAR, S.S. (1969) Hyperglycaemic non-ketotic coma following administration of Dilantin (Diphenylhydantoin). Diabetes, 18, 101.

Halmos, P.B., Nelson, J.K. \& Lowry, R.C. (1966) Hyperosmolar non-ketoacidotic coma in diabetes. Lancet, $\mathbf{i}, 675$.

HAYes, T.M. \& Woods, C.J. (1968) Hyperosmolar nonketotic coma. Lancet, i, 209.

HeNRY, D.P. \& BRESSLER, R. (1968) Serum insulin levels in non-ketotic hyperosmotic diabetes mellitus. American Journal of the Medical Sciences, 256, 150.

Johnson, R.D., Conn, J.W., Dykman, C.J. et al. (1969) Mechanisms and management of hyperosmolar com8 without ketoacidosis in the diabetic. Diabetes, 18, 111 .

Karmody, A.J. \& KYLE, J. (1969) The association betweem carcinoma of the pancreas and diabetes mellitus. Britis Journal of Surgery, 56, 362.

Kumar, R.S. (1968) Hyperosmolar non-ketotic coma. Lancet, $\mathbf{i}, 48$.

Maccario, M., Messis, C.P. \& Vastola, E.F. (1965) Focal seizures as a manifestation of hyperglycaemia without keto-acidosis. A report of seven cases with review of the literature. Neurology, 15, 195.

Pygott, F. \& Osborn, H. (1937) Pancreatic cancer with diabetes. Lancet, i, 1461.

SpenNey, J.G., Eure, C.A. \& KreisberG, R.A. (1969) Hyperglycaemic, hyperosmolar, non-ketoacidotic diabetes. A complication of steroid and immunosuppressive therapy. Diabetes, 18, 107.

VinIK, A.I., JofFe, B.I. \& JouberT, S.M. (1970) Metabolic findings in a patient with hyperosomolar non-ketotic diabetic stupor. British Medical Journal, 4, 155. 